\title{
Quality of experience in rural tourism: regional case studies in Austria and Germany
}

\author{
V. Melzer \& K. Meyer-Cech \\ Department of Landscape, Spatial and Infrastructure Sciences, \\ University of Natural Resources and Life Sciences Vienna, Austria
}

\begin{abstract}
The conducted research deals with factors of quality of tourism in relation to rural touristic initiatives, which conjointly market their tourism products. Several touristic initiatives were selected based on five criteria (e.g. a regional embeddedness and existence of a trademark) and their touristic offers were analysed. The study aimed to work out how these initiatives highlight their regional characteristics and which quality components contribute to a high quality of tourism experience. Based on the literature, four main components were identified that contribute to the quality of tourism, namely: hardware, environment/culture, software, and quality of experience. These components were combined with the seven instruments of quality of experience (e.g. the focus on a specific topic) by Müller and Scheurer (Tourismus-Destination als Erlebniswelt. Ein Leitfaden zur Angebots-Inszenierung, 2004) and tabulated. In the case study analysis, the quality requirements the touristic initiatives impose on their members, as well as existing offers, were gathered and assigned to the above-mentioned components of quality of tourism. The case study analysis revealed that all regional initiatives provide offers in all four main components. The initiatives also apply several aspects of the quality of experience, to highlight their regional characteristics. Several offers exist, in particular in the subcategories accommodation, culinary and regional products, events, information and internet presence as well as social media. In the field of quality of experience, the conveying of authenticity, the creation of atmosphere, and approaches of storytelling are used to generate attractions and to constitute positive guest experiences. This article provides first points of reference for an implementation of a universal guideline for regional touristic initiatives.
\end{abstract}

Keywords: rural tourism, quality of tourism, quality of experience, Austria, Germany. 


\section{Introduction}

Rural tourism destinations distinguish themselves by the fact that the sector is extremely fragmented and dominated by small, generally family run, enterprises. On the one hand this may result in a competitive disadvantage or else in often challenging efforts in concerted marketing activities of small businesses. On the other hand it is this fragmentation and semi-professionalism that is viewed as the very attraction of rural tourism destinations (see e.g. [2, 3]). This paper argues that both the atmosphere of rural host enterprises as well as their regional embeddedness strongly contribute to the quality of the tourist experience.

"Although there is much debate about the precise meaning of 'quality' in the context of sustainable rural tourism, there is general agreement among its key stakeholders that delivering quality is a key requirement for achieving success in rural tourism businesses." [3], p. 227. A review of literature on quality in tourism (e.g. [4-7]) gives insight into the main components of quality in tourism, such as material factors (e.g. natural and built environment), quality of service and even quality of experience - whereby the latter is not dealt with in the same level of detail and was therefore chosen as the main focus of this paper. Looking at rural touristic initiatives it is the goal of this article to identify quality components in terms of the staging of rural attractions and creating an intense and positive guest experience.

\section{Methodology}

A review of literature on topics such as tourist offer, quality in tourism, interpretation and creation of memorable tourist experiences as well as destination management was undertaken for two reasons: on the one hand in order to clarify the terms used in this paper and on the other hand to find those components of quality in tourism that are relevant for regionally embedded collective tourist initiatives. The extracted components of quality were illustrated in a chart (see Fig. 1) whose skeletal structure is based on Müller's [7] classification in hardware, environment/cultural aspects and software. These components were complemented by findings of Freyer [8], Opaschowski [5] and concerning heritage interpretation and the elements that enable a memorable tourist experience by the works of Beck and Cable [9] as well as Müller and Scheurer [1].

The empirical part of this paper draws on the examination of six case studies, namely collective tourist initiatives in Austria and Germany that can be considered as good practice examples in terms of staging special regional features (see 5). These case studies were chosen according to the following criteria: small scale, environmentally responsible collective initiative, strong relation to a regional entity or regional characteristics in terms of tourist marketing and branding, converting a special regional attraction into a memorable tourist experience, existence of a list of quality criteria that the members of the tourist initiative have to comply with, regional embeddedness (i.e. contribution to the regional economic value added), existence of a 
responsible organisation that is in charge of management and coordination and existence of a brand mark for the collective tourist offer in general and the destination in particular. The necessary data to describe the case studies and their lists of quality criteria was obtained in the year 2013 by reviewing the relevant websites, brochures and written communication with the persons in charge of managing the tourist initiatives.

The analysis of the case studies concentrated on finding good examples for staging regional characteristic features, such as an agricultural product, the cultural landscape, craftsmanship or life on a farm. These examples for successful staging were described according to the components of quality in Figure 1. By doing so, differences and commonalities between the case studies became evident (see 6.1). And it became clear in which areas many offers exist that enable a memorable tourist experience and in which areas there is a lack thereof. Finally recommendations were made for various stakeholders, e.g. tourist entrepreneurs or municipalities, on how to improve the quality of providing memorable tourist experiences with a strong regional relation in rural tourism.

\section{Clarification of terms}

\section{Rural tourist initiatives}

For the present paper, several tourist initiatives were selected as case studies. In most cases, the foundation of the tourist initiatives was initiated by the joint marketing of the respective tourist product. This product can be both a tangible good, one or more services or the marketing of an entire region. If several service providers (e.g. accommodation, farmers) incorporate and jointly offer a particular product (e.g. hiking or biking holiday, farm holiday), this can be seen as a tourist initiative, referred to as special interest group.

\section{Characteristics of tourism quality}

There is a lot of literature dealing with service quality (e.g. [4-8, 10]), where several determinants for service quality are defined. For this paper, three approaches are most relevant. The first approach comes from Opaschowski [5], who defines three main components of tourism quality, namely the natural quality, including i.a. landscape and climate, the tangible quality such as accommodation and restaurants, and the intangible quality, which comprises atmosphere, hospitality and friendliness. Freyer [8] describes similar categories. He divides the touristic product into original offer (e.g. landscape, culture, hospitality) and derived offer (e.g. accommodation, hiking paths, events). Furthermore, he mentions that the intangible offer such as experiences and atmosphere plays an important role for a high tourism quality. The third approach is Müller's [7] classification in hardware, environment/culture and software. Equipment, function and aesthetics are assigned to the hardware component. Landscape, pollution and culture/traditions belong to the component environment/culture and software involves service, information and hospitality. 
Opaschowski ([5], p. 115) points out that "the guest sets the standard for quality in tourism".

\section{Regional branding}

The term branding refers to the assignation of a brand to something, as in this case a tourist product. Trademarks serve to give a product, business, or an entire destination distinctiveness, they remain in the customer's mind [11]. A brand can give the guest an orientation aid, because it provides information on quality norms and standards, which makes it easier for the guest to assess the quality of the expected services. They provide information on quality norms and standards, as well as the benefits and guarantees [12]. All selected case studies of this paper have a recognizable brand name.

\section{Quality of experience}

Experiences are induced by specific environmental stimuli, especially by a change of the environment. The experience itself is a response to this stimulus. Experiences are often associated with the interaction with other people, but can also be created by other stimuli, such as odours, tastes or sounds, to which the person reacts with certain emotions [1]. The staging of experiences takes place at a certain location or in a particular environment, called "setting". The staging serves to design the experience setting, e.g. by highlighting a certain topic to create an appropriate atmosphere.

\section{Components of quality in tourism based on literature}

As a result of the literature review this chapter and figure 1 in particular give an overview over the components of quality in tourism. As mentioned above Müller's [7] classification in hardware, environment/cultural aspects and software was used as the skeletal structure. The "memorable tourist experience" (called "Erlebnisqualität" in German literature) is viewed as part of the software by Müller [7] and as part of the immaterial aspects by Opaschowski [5] and Freyer [8]. But in accordance with the focus of this paper the authors decided to depict the memorable tourist experience as a separate fourth component - even though some aspects of it can be viewed as part of the other three components. For example the accommodation (which belongs to the element of hardware) has to be designed in such a way that a certain atmosphere is created and the authenticity of the regional tourist offer is conveyed. Both atmosphere and authenticity are also integral parts of the memorable tourist experience.

The component hardware includes the sub items facilities, aesthetics/setting and function. A rural tourist destination may comprise of facilities for accommodation, catering, traffic and leisure activities. Facilities in rural tourism may be a winery, an alpine dairy or a handicraft business as well as local produce such as cheese or pumpkin seed oil.

The component environment/cultural aspects comprises of the landscape, socio-cultural aspects as well as litter and other forms of pollution. A landscape's scenery, its natural monuments as well as hiking and biking trails are predestined 
to be staged. By doing so attractive tourist experiences that involve all the senses are enabled. Local customs and events, which are ascribed to socio-cultural aspects, also offer manifold opportunities to stage the overall theme of the conjoint rural tourist initiative.

The quality element software is made up of the sub items service, information and hospitality. The latter not only includes the friendliness and skills of the staff, but also the external communication (e.g. a uniform appearance by establishing a corporate identity), which is another field in which the senses of the tourists are appealed to.

Finally the component of the memorable tourist experience involves all sorts of ways of staging the tourist offer: e.g. highlighting a specific theme, activating all the senses of the guests, getting the guests involved in activities and creating a certain atmosphere. Storytelling, i.e. all parts of the tourist offer represent pieces of an umbrella theme or story, is another instrument for successful staging [13]. In this context this paper also draws on the findings of heritage interpretation (see e.g. [9]), which focuses on the often interactive explanation of heritage sites using a wide range of modalities such as guided walks, staffed stations, signs, artwork, brochures, audio-guides and audio-visual media.

\begin{tabular}{|c|c|c|c|}
\hline \multicolumn{4}{|c|}{ Overall theme } \\
\hline Hardware & $\begin{array}{c}\text { Environm./ } \\
\text { cultural aspects }\end{array}$ & Software & $\begin{array}{c}\text { Memorable tourist } \\
\text { experience }\end{array}$ \\
\hline $\begin{array}{l}\text { - Facilities for } \\
\checkmark \text { accommodation } \\
\checkmark \text { catering } \\
\checkmark \text { traffic } \\
\checkmark \text { leisure activities } \\
\checkmark \text { buying souveniers } \\
\text { - Aesthetics/secenery } \\
\checkmark \text { typical architecture } \\
\checkmark \text { in line with the landscape } \\
\text { - Function } \\
\checkmark \text { capacity of facilities } \\
\checkmark \text { accessibility for } \\
\text { locomotively challenged } \\
\text { persons } \\
\checkmark \text { hygiene } \\
\checkmark \text { design }\end{array}$ & $\begin{array}{l}\text { - Landscape } \\
\checkmark \text { scenery of the landscape } \\
\checkmark \text { natural monuments } \\
\checkmark \text { hiking and biking trails } \\
\text { - Socio-cultural aspects } \\
\checkmark \text { regional value added } \\
\checkmark \text { local customs } \\
\checkmark \text { heritage sites } \\
\checkmark \text { events } \\
\text { - Disturbances and } \\
\text { pollution } \\
\checkmark \text { litter } \\
\checkmark \text { wise use of natural } \\
\text { resources }\end{array}$ & $\begin{array}{l}\text { - Service } \\
\checkmark \text { accommodation and } \\
\text { catering } \\
\checkmark \text { additional offers } \\
\checkmark \text { adequate price } \\
\text { - Information } \\
\checkmark \text { information site } \\
\checkmark \text { information material } \\
\checkmark \text { web presence } \\
\checkmark \text { marketing } \\
\checkmark \text { education and training } \\
\text { - Hospitality } \\
\checkmark \text { friendliness } \\
\checkmark \text { mentality } \\
\checkmark \text { courtesy } \\
\checkmark \text { reliability }\end{array}$ & $\begin{array}{l}\text { - Staging } \\
\checkmark \text { creating attractions } \\
\checkmark \text { highlighting a theme } \\
\checkmark \text { specific target group } \\
\checkmark \text { storytelling } \\
\checkmark \text { appealing to the senses } \\
\checkmark \text { enabling interactive } \\
\text { experiences } \\
\checkmark \text { creating an atmosphere } \\
\checkmark \text { authenticity } \\
\checkmark \text { uniqueness } \\
\checkmark \text { corporate identity (CI) }\end{array}$ \\
\hline
\end{tabular}

Figure 1: Components of quality in rural tourism (based on [7], complemented by [5] and [8], revised by the authors).

\section{Quality of tourism in the case studies}

From the six selected case studies five are Austrian examples. Three case studies use an agricultural product for regional branding, namely a Wine Trail, a Cheese Trail and an umbrella organisation concerned with establishing so-called "Genuss Regionen" or taste regions. One case study is an umbrella organisation for marketing regionally typical craftsmanship and another for marketing farm 
tourism. The sixth case study was chosen from Germany, it is an organisation that conveys a quality label for socially and environmentally responsible tourism not only to single enterprises, but - and this is interesting for this paper - to towns and nature parks.

The Wine Trail in Lower Austria is one of the longest trails worldwide following the topic of wine. It has $830 \mathrm{~km}$ in length and guides through eight wine regions including more than 150 wine villages. The Cheese Trail, which is located in the Austrian state Vorarlberg, is an incorporation of businesses (e.g. farmers, cheese manufacturers), who conjointly market cheese products and want to display the cheese production, the cheese consumption and the landscape in such a way that memorable experiences for the guests are created. The "Meisterstrasse Austria" is not a specific trail, but an association of about 350 Austrian handicraft businesses in various industries (e.g. textiles, housing, jewellery). The organisation "Genuss Region Österreich" includes 110 regions in Austria, which promote a certain lead product that is typical for the respective region. The labelling as such a taste region is carried out by the Federal Ministry of Agriculture, Forestry, Environment and Water Management in Austria. The initiative promoting farm holidays consists of about 2600 farms providing specific offers (e.g. bio-farms, baby-farms, accessible farms) for different target groups. "Viabono" is a German certificate for environmentally friendly and sustainable holidays. Members include accommodation, catering businesses, destinations, towns and nature parks.

The objectives of all case studies are to market regional products, to preserve culture and traditions, to coordinate tourism activities and to promote interregional cooperation. Furthermore, the rural tourist initiatives want to contribute to the strengthening of regional identity and hospitable attitude of all members and partners as well as to the regional value added.

\subsection{Requirements for members of the rural tourist initiative}

Only those rural tourist initiatives were selected as case studies, which have a set of quality criteria their members have to respond to. For example the management organisation of the Wine Trail formulated a comprehensive catalogue including mandatory and optional quality criteria, whereas the Cheese Trail created a brochure containing guidelines for quality. Both documents include criteria for different actors (e.g. accommodation and gastronomy businesses, wineries, alpine dairies, hosts of events) concerning

- the overall appearance of the locality,

- the theme-specific touristic information for guests as well as signage,

- the regional and typical products,

- the qualified and friendly employees,

- the cleanliness and hygiene.

The quality requirements of the initiative "Genuss Region Österreich" concern the agricultural product, the region as well as the marketing, accommodation and gastronomy businesses within the taste regions. In order to 
become a taste region, an application must be submitted to the Ministry and a jury decides on the award. Subsequently, an agreement between the region and the Ministry is created.

The procedure to become a member of the initiative for farm holidays is similar. In a categorization process, the entire farm is reviewed in the areas of quality of equipment, quality of service, quality of memorable tourist experience as well as general farm condition and cleanliness. The farms are divided into three quality categories, which are illustrated by flowers. Two flowers represent a satisfying, three flowers a good and four flowers a very good quality.

To become a member of the "Meisterstrasse Austria", a craft business must complete the partner agreement and pay a membership fee. By signing the partner agreement, the owner of the craft business also obliges to comply with certain quality criteria. There are criteria concerning products, but also for the craft businesses.

"Viabono" has several certification concepts for their different members, e.g. hotels, gastronomy or nature parks, whereby the latter are most relevant for this paper. The application documents for nature parks include the categories of nature-based recreation, management, information and education, regional economic flows as well as mobility, waste, energy and climate, water, and architecture. An applicant is awarded points for fulfilling mandatory and optional criteria, whereby there is a minimum number of points that must be achieved.

\subsection{Quality criteria and examples for staging}

The touristic offer of the case studies was analysed and good examples for staging regional characteristics were collected based on the quality components in rural tourism shown in Figure 1.

Within the hardware component, all the examples generally have a good offer, but a few examples can be highlighted positively. The Wine Trail has several wineries, where guests can visit the wine cellar, find out interesting facts about wines and the production as well as tasting wines. The Cheese Trail also has dairies, which can be visited, including tasting and information about the typical traditional cheese production in the region. The accessibility for physically challenged people also belongs to the hardware component. Here the tourist initiative for farm holidays must be emphasized, as they provide specific offers for this challenged target group. Additionally, the font size of the homepage can be changed individually. The other examined case studies have at least some approaches relating to accessibility. The Wine Trail, the Cheese Trail and "Viabono" have barrier free hiking paths, but there is hardly any other information about this issue.

Regarding the component environment/cultural aspects, there is a huge offer of different events. On particularly beautiful sites in the middle of the wine yards a kind of banquet with a special menu, different wines and live music is organized by the Wine Trail Lower Austria. One member of the Wine Trail organizes a crime walking tour through the vineyards, where guests have to solve a murder case. Furthermore, the taste regions of the initiative "Genuss Region Österreich" take part in a series of events, so called "gusto weeks" at specified 
times each year, where seasonal menus are offered. Another event series of the taste regions is a tour with e-bikes to defined "gusto places". A good example for creating memorable tourist experiences is the Christmas market, organized by the "Meisterstrasse Austria", where handicraft businesses present their products.

Within the component software, most offers exist for the subcategory information. All case studies use the internet as an information platform, On the one hand, all examined rural tourist initiatives have one or more websites, but they additionally all use social media like Facebook on the other hand, where they present pictures or announce events. Furthermore, a wide range of printed information material is available for the Wine Trail (e.g. a detailled catalogue listing all members, their features and events) and for the taste regions (e.g. brochures about the lead product). The "Meisterstrasse Austria" and the initiative for farm holidays also publish catalogues listing their member businesses. Some initiatives provide an online shop, where the regional products can be bought.

\section{Conclusions}

In a first step in this following chapter, the differences and commonalities between the case studies are shown by comparing their respective quality components. This juxtaposition enables to determine those areas in which many offers exist and where there is a lack thereof. In a second step, recommendations for the future are stated.

\subsection{Contrasting juxtaposition of the quality components of the case studies}

The analysis of the case studies showed that there are offers in all four main quality components (hardware, environment/culture, software, quality of experience) and that all case studies use instruments of staging regional characteristic features.

Referring to the instruments for staging these regional characteristic features, it was found out that the initiatives put their emphasis on promoting authentic and regional embedded offers. All rural tourist initiatives highlight a specific topic (agricultural or handicraft product, life on a farm, nature park) and also include the landscape that is typical for the region. In this context it can be stated that all case studies display their tourist offer by means of telling a story: the story of where a certain agricultural or artisan product comes from and how the people live who produce it, the story of life on a farm or the story of the plant and animal inhabitants of a natural habitat. The element of storytelling used in this manner helps to fascinate the guests, lets them enter another world different from their everyday lives.

Examples, where staging is particularly well applied, are the crime walking tour example through the vineyards, as well as the banquets with wines and regional culinary specialties accompanied by live music. For these events, the staging instruments storytelling and creating atmosphere are implemented.

The possibility to visit wineries or alpine dairies creates memorable experiences for the guests by enabling the interactive participation in those 
activities. Furthermore, the traditional production methods are authentically conveyed to the guest by these visits. Some case studies offer tastings of their regional delicacies, thus appealing to the senses.

Figure 2 gives an overview of those instruments of staging regional characteristic features, which are used the most by the examined rural tourist initiatives.

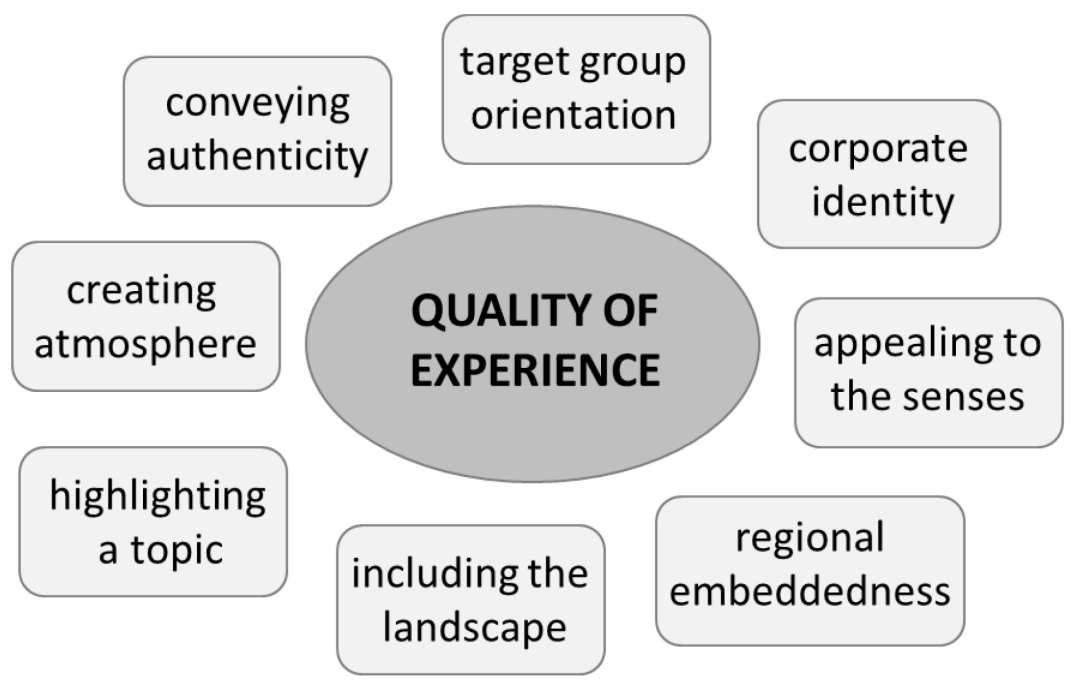

Figure 2: Most used instruments of staging of the examined case studies (compilation by the authors).

Differences between the case studies can be found concerning their inclusion of accommodation into the tourist offer in general and into their efforts of staging the tourist offer in particular. The spectrum ranges from the umbrella organization for farm holidays that deals with creating a certain atmosphere in the offered rooms in great detail over the Wine Trail, that has a few so-called wine hotels that set value on telling the story of wine, to the Meisterstrasse, that does not include accommodation in its tourist offer.

Another great difference between the case studies can be found in how they deal with regional embeddedness and geographical concentration. The first group consists of two case studies, namely the organization for farm holidays and the Meisterstrasse: they do place value on the local/regional setting, but their members are not all from the same geographical region. Rather they can be found throughout Austria. The next group places most emphasis on the geographical region, i.e. the label Viabono for the category of nature parks. And the last group contains the collective tourist initiatives that are made up of a whole group of regional stakeholders that all come from the same geographical region. 


\subsection{Recommendations}

The research on this paper has shown that it is essential for rural tourist initiatives to strengthen the cooperation with regional stakeholders from different sectors (tourism, trade, agriculture, gastronomy, etc.) in order to persist in the tourism market. Additionally, successful tourist initiatives ensure the regional value added by national and international marketing of their products and services.

Rural tourist initiatives could also think about benefitting from new markets, such as social media and communication technologies (smartphones, tablets). There is already an extensive presence in social media, but applications for smartphones and tablets are hardly available.

Furthermore, the authors recommend to profile an umbrella organisation for rural tourist initiatives and to use strategies of destination management in order to coordinate the diverse actors and to guarantee certain quality standards. Some studies [12, 14] emphasize that a brand creates trust, conveys values and contributes to the identification of the guest with the brand/initiative.

Education and training of staff is also very important to meet the continually increasing demands of guests. Motivated and competent employees are substantial for a high quality of the tourist product, which is also confirmed by Opaschowski [5] and Müller [7]. In this context, the mandatory participation in training courses would prove as useful, as the Cheese Trail has already formulated in their quality criteria. Even regular information sessions and meetings to exchange experiences between the various stakeholders are recommended.

However, it is not sufficient only to formulate quality requirements for the members of the tourist initiative. To ensure that the quality of the tourist product can also be obtained, quality assurance is important. Opaschowski [5] claims a quality seal for quality tourism. Guest evaluation and feedback should also be part of the quality management in order to guarantee the maintenance of quality standards and to enable improvements. Müller and Scheurer [1] see guest evaluation as one of their seven instruments of quality of experience. Besides the guest evaluation, they outline that a concept for the staging of the specific topic should be created, including the objectives of the initiative, the subject, the lead products and a definition of the relevant target groups. It seems useful for rural tourist initiatives to include the aspect of quality of experience into the requirements for members.

When staging rural attractions, however, caution is advised, as an overstated staging may cause the loss of authenticity. In which way staging is carried out, is based on the natural conditions of the destination or region. It is important for the guest that the instruments used for staging regional characteristic features should be related to his or her stay and should be convincingly conveyed. Furthermore, the experience setting should also be based on the existing regional natural and cultural characteristics in order to enable a high quality of experience for the guest. The guest recognizes the difference between authentic, well-staged experience settings and inauthentic, overstated or poorly staged experience settings with certainty $[13,15]$. 


\section{References}

[1] Müller, H., Scheurer, R., Tourismus-Destination als Erlebniswelt. Ein Leitfaden zur Angebots-Inszenierung. FIF Universität Bern, Bern, 2004.

[2] Meyer-Cech, K., Themenstraßen als regionale Kooperationen und Mittel zur touristischen Entwicklung - fünf österreichische Beispiele, thesis at the University of Natural Resources and Life Sciences Vienna: Vienna, 2003.

[3] Youell, R. \& Wornell, R., Quality as a Key Driver in Sustainable Rural Tourism Businesses, Aspects of Tourism 26: Rural Tourism and Sustainable Businesses, Eds. Hall, D., Kirkpatrick, I., Mitchell, M., Channel View Publications, Clevedon, pp. 227-248, 2005.

[4] Parasuraman, A., Zeithaml V. A., Berry, L. L., A Conceptual Model of Service Quality and 1st Implications for Future Research, Journal of Marketing (49), 41-50, 1985.

[5] Opaschowski, H.W., Das gekaufte Paradies - Tourismus im 21. Jahrhundert, B·A·T Freizeit-Forschungsinstitut GmbH (Ed.), Germa Press: Hamburg, 2001.

[6] Bruhn M., Stauss B. (Eds.), Dienstleistungsqualität - Konzepte Methoden - Erfahrungen, 3. Auflage, Gabler Verlag: Wiesbaden, 2000.

[7] Müller, H., Qualitätsorientiertes Tourismus-Management. Wege zu einer kontinuierlichen Weiterentwicklung. Haupt Verlag: Bern Stuttgart Wien, 2004.

[8] Freyer, W. (Eds.), Tourismus - Einführung in die Fremdenverkehrsökonomie. $8^{\text {th }}$ edition, Oldenbourg Verlag: München Wien, 2006.

[9] Beck, L., Cable, T.T., Interpretation for the 21st Century - Fifteen Guiding Principles for Interpreting Nature and Culture, Sagamore Publishing: Champaign, 2002.

[10] Voigt, H.D., Mockenhaupt, A., Qualitätssicherung, Qualitätsmanagement. praxisnah - anwendungsorientiert. 3rd, completely revised edition. Verlag Handwerk und Technik GmbH: Hamburg, 2010.

[11] Meffert, H., Burmann, C., Koers, M. (Eds.), Markenmanagement Grundlagen der identitätsorientierten Markenführung, Gabler Verlag: Wiesbaden, 2002.

[12] Ferner, F-K., Pötsch, W., MarkenLust und MarkenFrust im Tourismus Techniken, Strategien, Design und Praxis beim Aufbau und Management von Tourismusmarken, Österreichischer Wirtschaftsverlag: Wien, 1998.

[13] Egenter, S., Natur in Szene gesetzt - das Erlebnis beginnt! Erlebnismanagement im naturnahen Tourismus, VDM Verlag Dr. Müller: Saarbrücken, 2007.

[14] Deutscher Verband für Landschaftspflege (DVL) e.V., Landschaft vermarkten - Leitfaden für eine naturverträgliche Regionalentwicklung, DVL-Series "Landschaft als Lebensraum”, Issue 10, 2006.

[15] Steinecke, A., Treinen, M. (Eds.), Inszenierung im Tourismus - Trends Modelle - Prognosen. ETI-Studien Band 3, Europäisches Tourismus Institut GmbH: Trier, 1997. 